\title{
Freire e Vigotski no contexto da Educação em Ciências: aproximações e distanciamentos
}

Freire and Vigotski's in the context of Science Education: proximities and detachments

\author{
Simoni Tormöhlen Gehlen ${ }^{1}$ \\ Milton Antonio Auth ${ }^{2}$ \\ Décio Auler ${ }^{3}$ \\ Maria Cristina Pansera-de-Araújo ${ }^{4}$ \\ Otavio Aloisio Maldaner ${ }^{5}$
}

\begin{abstract}
Resumo
No contexto da Educação em Ciências, as concepções de Paulo Freire e Lev S. Vigotski, individualmente, têm contribuído para a configuração de novas perspectivas de análise e teorização do conhecimento científico produzido e apropriado pelos sujeitos. O estudo teórico apresentou indicativos de que as idéias de Freire e Vigotski aproximam-se em três aspectos: a) a valorização do conhecimento cotidiano; b) as semelhanças entre o papel dos especialistas em Freire e dos sujeitos mais capazes em Vigotski e c) a conscientização; e apresentam distanciamentos em dois: a) na gênese do conhecimento e b) no ponto de partida do processo de aprendizagem. Além do mais, sinaliza-se que a possível complementaridade das idéias dos autores pode enriquecer propostas curriculares para a Educação em Ciências.
\end{abstract}

Palavras-chave: Conhecimento cotidiano e científico. Gênese do conhecimento. Educação em Ciências.

\footnotetext{
Abstract

In the context of Science Education, the conceptions of Paulo Freire and Lev S. Vigotski have contributed individually to the shaping of new perspectives of analysis and theory of scientific knowledge that is produced and incorporated by individuals. This theoretical study indicates that on one hand Freire and Vigotski' ideas converge in three aspects: a) valorization of daily knowledge; b) similarities between the role of specialists in Freire and the role of more able individuals in Vigotski and c) awareness. On the other hand, the scholar's ideas diverge in two aspects: the knowledge genesis and $b$ ) the starting point of learning process. Moreover, the possible complementarity of both Freire and Vigotski's ideas may improve curricular proposals in Science Education.

Keywords: Daily and scientific knowledge. Knowledge genesis. Science Education.

${ }^{1}$ Doutoranda do Programa de Pós-Graduação em Educação Científica e Tecnológica da UFSC simoni@ced.ufsc.br

${ }^{2}$ Professor Dr. do DeFEM e Mestrado em Educação nas Ciências, Unijuí - auth@unijui.edu.br

${ }^{3}$ Professor Dr. do MEN/PPGE/CE/UFSM - auler@ce.ufsm.br

${ }^{4}$ Professora Dra. do DBQ e Mestrado em Educação nas Ciências, Unijuí - pansera@unijui.edu.br

${ }^{5}$ Professsor Dr. do DBQ e Mestrado em Educação nas Ciências, Unijuí - maldaner@unijui.edu.br
} 


\section{Introdução}

No Brasil, o aporte de referenciais como a abordagem histórico-cultural com base em Vigotski e a abordagem freireana tem balizado estudos no âmbito educacional. Por exemplo, na Educação em Ciências, a influência da perspectiva vigotskiana apresenta subsídios a pesquisas que investigam aspectos como: a construção e desenvolvimento de significados mediante a utilização da linguagem (AGUIAR; MORTIMER, 2005; MORTIMER; SCOTT, 2002; FERREIRA; JÚNIOR, 2005; MORTIMER, 2000) e a configuração de propostas curriculares (PANSERADE-ARAÚJO; AUTH; MALDANER, 2005; MALDANER; ZANON, 2001). Os estudos com aporte dos pressupostos de Freire apontam para contribuições como aquelas relacionadas à reorientação curricular e reflexões acerca da prática docente, a saber: Angotti, (1991); Auler (2002); Coelho (2005); Delizoicov (1991); Delizoicov; Angotti (1991); Delizoicov; Angotti; Pernambuco (2002); Pernambuco et al (1988) e Silva (2004).

O cenário apresentado revela que os pressupostos de Freire e Vigotski, de forma individual, vêm delineando a maioria das pesquisas brasileiras. Ou seja, adotase um ou outro referencial como principal aporte dos estudos. Situação análoga é descrita, em âmbito internacional, por Rodríguez Arocho (2000), que em revisão bibliográfica deparou-se com um vasto número de referências particulares a Vigotski, constatando que raros são os trabalhos que mencionam esse autor em conjunto com Freire ou que, de alguma forma, vinculam suas idéias. Estudos em âmbito nacional, contudo, buscam a articulação entre os pressupostos desses autores, a exemplo de Marques e Marques (2006) e Moura (2001). Essas pesquisas, no entanto, são realizadas no âmbito da área de Educação e poucas são aquelas que articulam as idéias de Freire e Vigotski na Educação em Ciências. Diante disso, tentativas têm sido realizadas no contexto de um projeto interinstitucional de pesquisa intitulado "Desenvolvimento do ser humano em contextos complexos, marcados pela CiênciaTecnologia, nos processos de ensino e aprendizagem ", 6 no período de agosto de 2004 a julho de 2005, envolvendo os grupos de pesquisa Gipec/Unijuí e GETCTS/UFSM. ${ }^{8}$

\footnotetext{
${ }^{6}$ Com apoio financeiro da Fapergs.

7 Grupo Interdepartamental de Pesquisa sobre Educação em Ciências, vinculado à Universidade Regional do Noroeste do Estado do Rio Grande do Sul - Unijuí.

${ }^{8}$ Grupo de Estudos Temáticos em Ciência-Tecnologia-Sociedade, vinculado à Universidade Federal de Santa Maria.
} 
Esses coletivos, apesar de trabalharem com referenciais distintos, respectivamente, Lev S. Vigotski, Paulo Freire e os pressupostos do movimento Ciência Tecnologia e Sociedade (CTS), buscam aproximações e contribuições entre as idéias desses autores.

Algumas aproximações e distanciamentos foram explicitados durante 0 desenvolvimento do projeto e proporcionaram respaldo teórico ao presente artigo. Trata-se, agora, de aprofundar isso no campo teórico para melhor entender o campo empírico, mesmo não sendo o escopo deste trabalho. O objetivo consiste em discutir e sistematizar possíveis aproximações e distanciamentos entre as idéias de Freire e Vigotski no contexto da Educação em Ciências. Nossa hipótese é que as idéias dos autores se complementam tanto nas diferenças quanto nas similaridades. A intenção não é contrapor e nem comparar as teorias de Freire e Vigotski, mas sinalizar que juntas podem aglutinar ainda mais contribuições para o processo educacional.

As articulações teóricas tornaram-se possíveis mediante ações sistemáticas de leituras, discussões e análise de obras referentes à abordagem freireana e vigotskiana, proporcionadas pelos encontros dos grupos Gipec/Unijuí e GETCTS/UFSM, no âmbito do projeto interinstitucional, e pelo trabalho de Gehlen (2006).

\section{Contribuições de Freire e Vigotski}

Para favorecer a discussão sobre as possíveis articulações entre o pensamento de Freire e de Vigotski, num primeiro momento é de fundamental importância uma reflexão mais sistemática em torno dos pressupostos dos autores. Para tal, com base em Gehlen (2006), organizou-se dois esquemas-síntese sobre a formação da consciência das pessoas, passíveis de serem modificados/aprofundados, como orientadores e organizadores das análises e sistematizações futuras (Quadro 1).

Ressalta-se que ao trazermos à tona quaisquer aspectos relativos às idéias de Freire e Vigotski, estamos cientes de que ambos produziram suas obras em contextos históricos e geográficos diferenciados; Freire, educador brasileiro, viveu de 1921 a 1997 e escreveu suas primeiras obras numa época em que aflorava a ditadura militar; Vigotski, psicólogo russo, viveu de 1896 a 1934 e produziu seus trabalhos no período pós Revolução-Russa. 


\section{Esquema I}

Vigotski - Cultura Científica $\rightarrow$ Sistema Conceitual $\rightarrow$ Consciência

Esquema II

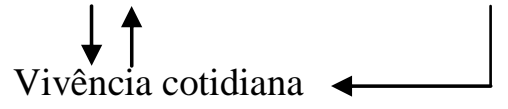

Freire - Vivência/Problematização $\rightarrow$ Investigação Temática $\rightarrow$ Redução Temática

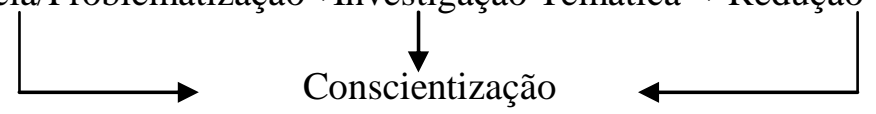

Quadro 1: Esquemas-síntese e organizadores das idéias de Vigotski e Freire

O esquema I compreende movimentos possíveis a partir da teoria de Lev S. Vigotski e o esquema II sobre concepções de Paulo Freire. Entendemos que ambos podem apresentar questões pertinentes no contexto de propostas curriculares para a Educação em Ciências.

\section{A contribuição de Vigotski}

Na Educação em Ciências as idéias de Vigotski têm auxiliado a configurar novas perspectivas teóricas, considerando o contexto social do estudante. Este autor, embora enfatizando trabalhos no campo da Psicologia, interessou-se, também, pela Pedagogia e por outras áreas, como Artes, Literatura, Direito, Filosofia e História, o que reflete seu percurso marcado pela inter transdisciplinaridade. Ele atribui papel especial ao contexto social dos sujeitos, destacando o sujeito histórico-cultural, que interage com os objetos mediado por sistemas de signos. As interações e significações que ocorrem com base no emprego dos signos dão origem às funções psicológicas superiores, como memória e atenção voluntárias, raciocínio, abstração, representação, entre outras.

Nessa perspectiva, a constituição do sujeito e de suas características individuais, como personalidade, hábitos, modos de agir e capacidade mental dependem de interações com o meio social em que vive (REGO, 2000). O ser humano passa a ser um agente interativo na criação de seu contexto cultural, na medida em que também é por este constituído. Assim, a cultura torna-se parte da natureza humana, e passa a evoluir a partir das interações que vão sendo estabelecidas entre os sujeitos participantes. 
Ao defender a tese de que o ensino proporciona o desenvolvimento da mente e a constitui em novas dimensões, Vigotski (2001) defende que as funções psicológicas superiores emergem quando os sujeitos participam de processos sociais, como são os processos escolares no desenvolvimento do pensamento conceitual. Os processos sociais ocorrem, inicialmente, entre as pessoas ou em âmbito intermental, e, posteriormente, no plano pessoal ou intramental.

Ao ampliar os estudos sobre a teoria de Vigotski quanto ao ensino, tendo como referência o esquema I (Quadro 1), colocamos em evidência o primórdio do processo. Para o autor, no ensino dos sistemas de conhecimentos a criança aprende algo que não está diante de seus olhos, que excede em muito sua experiência imediata real e até mesmo potencial. Nesse caso, os conceitos científicos, caracterizados como sistemáticos na formação de sistemas hierárquicos, lógicos e coerentes, são “os portões através dos quais a tomada de consciência penetra no reino dos conceitos infantis” (VIGOTSKI, 2001, p. 195). Isso significa que a criança passa a tomar consciência de suas vivências por intermédio da significação dos conhecimentos sistematizados, a exemplo dos científicos.

Vigotski, ao enfatizar o abstrato, tinha em mente a via do conhecimento sistematizado (DUARTE, 2000), bem evidente desde o início dos processos sistemáticos de aprendizagem, o que abre margem para a interpretação de que seu ponto de partida estava direcionado à cultura científica. A significação dos conceitos sistematizados, para a tomada da consciência, entretanto, só seria possível se houvesse experiência anterior dos aprendizes do período pós-revolução socialista. Esta, provavelmente era suposta como impregnada de vivência política com ideais de "homem socialista”, com mais justiça e igualdade. Assim, os conceitos das Ciências Sociais eram vistos como importantes produtores de sentidos no contexto em revolução e evolução. Da mesma forma, em sua produção teórica, a preocupação girava em torno da compreensão da relação pensamento e linguagem, superando as dicotomias existentes nesses dois campos.

Na Rússia socialista da década de 1920, segundo Daniels (2003), a modernização ampla exigia formulações claras de uma vida melhor e à escola caberia proporcionar o entendimento do conceito de qualidade de vida acenado por sua aceleração. Ou seja, que fosse capaz de garantir a disponibilidade do equipamento conceitual para esse novo mundo mediante a formação de pessoas capazes de atuarem nesse novo mundo tecno-social. Logo, “a escola deveria ser a agência estatal para 
garantir o desenvolvimento de ferramentas conceituais avançadas” (DANIELS, 2003, p.71).

Nessa época, a sociedade valorizava a ciência e esperava dela a solução para os problemas sociais e econômicos do povo soviético (COLE; SCRIBNER, 1998). Segundo Rosa e Montero (2002), o objetivo da atividade revolucionária consistia na construção de uma nova sociedade e, dentro dela, de uma nova ciência. Isso, entretanto, não seria fácil de ser alcançado, uma vez que, nessa época, parcela expressiva da população da Rússia (cerca de 30\%) era analfabeta, e em determinadas regiões sequer havia alguma pessoa alfabetizada.

Vigotski via no materialismo histórico dialético de Marx uma fonte importante de entendimento da problemática da época. Nas suas elaborações teóricas, adota a abstração como fundamento para a aprendizagem/produção do conhecimento sistematizado, pois conforme Duarte (2000, p. 86), “a abstração é uma mediação indispensável pela qual a ciência chega à essência da realidade concreta”. O concreto só pode ser adequadamente captado pelo pensamento enquanto ponto de chegada, e não de partida. Vigotski, por várias vezes, fez referência à seguinte passagem de Marx para defender a importância do “método da abstração” na Psicologia, assim como em todas as ciências.

O concreto é concreto porque é síntese de muitas determinações, isto é, unidade do diverso. Por isso o concreto aparece no pensamento como o processo da síntese, como resultado, não como ponto de partida, ainda que seja o ponto de partida efetivo e, portanto, o ponto de partida também da intuição e da representação. No primeiro método, a representação plena volatiliza-se em determinações abstratas, no segundo, as determinações abstratas conduzem à reprodução do concreto por meio do pensamento (Marx, 1978, apud Duarte, 2000, p. 93).

Na dialética de Marx, no que se refere às relações entre o lógico e o histórico de um objeto, Duarte (2000) observa que o pensamento humano analisa a lógica da fase mais desenvolvida do objeto e vai até a história. Tal movimento ocorre para compreender a gênese desse objeto e as fases anteriores do processo histórico. Em seu entender, a análise histórica aprofunda a compreensão da fase mais desenvolvida, tornando ainda mais rica a reprodução do concreto pelo pensamento, reprodução essa que requer a mediação das abstrações. Sob essa ótica, o desenvolvimento da criança precisa partir do mais desenvolvido para o menos, dos conceitos sistematizados para os conceitos do cotidiano, o que constitui a chave para a compreensão do desenvolvimento infantil na interação da criança com o adulto.

Seguindo o esquema I, o Sistema Conceitual é a etapa em que os conhecimentos científicos e cotidianos exercem influência uns sobre os outros. 
Segundo Vigotski (2001, p. 348), “no pensamento infantil, não se separa os conceitos adquiridos na escola dos conceitos adquiridos em casa”. Os conceitos constituem um sistema de relações e generalizações contido nas palavras e determinado por um processo histórico-cultural.

Os conceitos cotidianos são aqueles que o estudante internaliza a partir do meio em que vive, mediante interações com pessoas da família, com grupos de amigos, com vizinhos, entre outras possibilidades no seu contexto. Ou seja, são conceitos construídos com base na observação, manipulação e vivência direta dos sujeitos e compreendidos como uma construção social, mediada pela interação com o outro (REGO, 1995). Nesse contexto, todavia, os conceitos constituem-se de forma assistemática, vagamente definidos e impregnados de vivência, sem formar consciência deles. Esses conceitos constituem a base do desenvolvimento, na mente da criança, de estruturas importantes de generalização, sem as quais os conhecimentos sistematizados não seriam possíveis.

Compreendemos, com base em Vigotski (2001), que no processo de formação dos conceitos científicos e cotidianos não há uma linha de ruptura em sua evolução. Os conceitos científicos e cotidianos se relacionam e se influenciam, sem transformação do conhecimento cotidiano em científico, o que permite a evolução de ambos. Vigotski defende a existência de vínculos e movimentos em sentidos opostos entre eles.

[...] o conceito espontâneo da criança se desenvolve de baixo para cima, das propriedades mais elementares e inferiores a superiores, ao passo que os conceitos científicos se desenvolvem de cima para baixo, das propriedades mais complexas e superiores para as mais elementares e inferiores (Vigotski 2001, p.348).

Para explicar esses movimentos o autor lançou mão da analogia do aprendizado da língua estrangeira. A criança aprende esta língua de uma forma diferente do aprendizado da língua materna, pois ocorre numa via oposta, na qual primeiramente aprende as estruturas superiores da língua, começando pelas palavras para as quais já domina um conceito, com a construção de frases e estrutura gramatical. Isto é, desenvolvem-se antes as propriedades vinculadas à tomada de consciência e à intenção e depois aquelas ligadas ao emprego inconsciente e não intencional da fala.

Nesse caminho diferenciado dos dois tipos de conceitos, a aprendizagem científica não se configura como uma mudança conceitual, mas como a "passagem de 
uma forma de conceituar para outra” (POZO et al, 1991, p. 89). Esse fato possibilita que os conhecimentos alcancem novos níveis de desenvolvimento, ou seja, evoluam em significado, passando a níveis mais abstratos. Os conceitos, ao evoluírem em significado, tornam possível a consciência conceitual, o que seria o ponto de chegada em nosso Esquema I. Desta maneira, a tomada de consciência "se realiza através da formação de um sistema de conceitos, baseado em determinadas relações recíprocas de generalidade, e que tal tomada de consciência dos conceitos os torna arbitrários” (VIGOTSKI, 2001, p.295). Assim, não há transformação de um sistema de conceitos em outro, como muitas vezes é entendido quando se parte de conceitos do cotidiano na educação escolar, mas uma influência recíproca que permite a evolução de ambos em suas vias próprias e diferenciadas.

\section{A contribuição de Freire}

Outro educador de grande relevância, no campo educacional, é Paulo Freire, contudo seus pressupostos têm sido bastante negligenciados na Educação em Ciências. Uma apropriação bastante livre de algumas de suas idéias permitiu construir o Esquema II (Quadro 1), e que será seguido para a discussão que serve aos propósitos de nosso estudo, especialmente, no que diz respeito à complementaridade às concepções vigotskianas para a educação científica escolar.

Em Freire (1987, 1993, 1996), compreendemos que o ponto de partida do processo educacional está vinculado à vivência dos sujeitos, seus contextos, seus

problemas, suas angústias e, acima de tudo, às contradições presentes no "mundo vivido”. Considerando a educação como um ato político, no sentido de estar engajada em ações transformadoras, a qual consiste na construção/elaboração do conhecimento de forma crítica pelos excluídos, este educador enfatiza como fundamental levar em conta o "saber de experiência feito" como ponto de partida.

Freire propôs uma educação que estimulasse a colaboração, a decisão, a participação, a responsabilidade social e política e, acima de tudo, a constituição de um sujeito autônomo. Falava em educação como um ato de transformação, da necessidade tanto do aluno conhecer os problemas sociais que o afligiam quanto de se estimular o povo a engajar-se na vida pública.

Nesse sentido, segundo Freire e Macedo (1990), a alfabetização é vista como uma forma de política cultural, uma vez que esta não se concretiza pelo simples ato de juntar letras e palavras. Para estes autores, é preciso ir além dessa compreensão e 
começar a pensá-la como a relação entre os educandos e o mundo de uma forma crítica e transformadora. Faziam parte da dinâmica pedagógica de Freire perguntas problematizadoras em torno da subjetividade das coisas, da razão de elas serem ou não serem, de suas finalidades, no seu contexto. Questionamentos como: O quê? Por quê? Como? Para quê? Por quem? Para quem? Contra quê? Contra quem? A favor de quem? A favor de quê? (FREIRE, 2001, p. 38) permeavam as discussões em que os educandos eram desafiados a perceberem as injustiças que os oprimiam e a necessidade de lutar por mudanças. Ou seja, Freire passou a problematizar, mediante a ação dialógica, o “mundo da vida” dos educandos.

A dinâmica pedagógica adotada por Freire no processo de alfabetização, acerca de uma pedagogia de inclusão, começou no início dos anos 60, quando, no Brasil, afloraram as manifestações sociais. Tais movimentos objetivavam romper com as tradições arcaicas, autoritárias, discriminatórias e elitistas vigentes, em busca de justiça, igualdade e dignidade. Nesse contexto efervescente, de anseio pelas mudanças sociais e políticas, suas concepções foram vistas como uma ameaça pelas classes dominantes, motivo pelo qual foi exilado por cerca de 16 anos.

Freire (1987) sempre destacou a importância da dialogicidade, posto que o diálogo 9 entre educador e educando é o aspecto fundamental para a problematização de situações reais vividas pelo educando. Santos (2002, p. 46), analisando pressupostos freireanos, destaca que o "diálogo não é o que impõe, o que maneja, mas o que desvela a realidade. Daí a importância da problematização”. No entendimento de Freire (1987), problematizar consiste em abordar questões que emergem de situações que fazem parte da vivência dos educandos. É desencadear uma análise crítica sobre a "realidade problema", para que o educando perceba esta questão e reconheça a necessidade de mudanças.

No momento da problematização é de fundamental importância estimular a curiosidade do ser humano que, segundo Freire (1996, p.87), "me faz perguntar, conhecer, atuar, mais perguntar, reconhecer”. Para este autor, a construção ou a produção do conhecimento implica o exercício da curiosidade, para que os professores e educandos se assumam epistemologicamente curiosos.

Ao problematizar busca-se trazer o "saber da experiência” dos estudantes, não como algo a ser desprezado ou ignorado, mas como ponto de partida, uma vez que é a

\footnotetext{
${ }^{9}$ Para Freire (1987), nessa etapa é que começa a formação da nova percepção e do novo conhecimento, relacionado à “consciência máxima possível”.
} 
compreensão do mundo em que vivem os estudantes que necessita ser considerado no início do processo de alfabetização. Dessa forma, ao valorizarmos seus conhecimentos estamos trazendo para a escola muito mais do que temas a serem estudados, mas também aspectos histórico-culturais, políticos e ambientais do educando e da comunidade escolar. Desconsiderar esses aspectos é voltar-se para uma escola desvinculada da realidade, vazia de significado.

Freire (1993, p.70), no entanto, esclarece que partir desses conhecimentos não significa ficar neles, mas sim buscar novos.

[...] partir do saber que os educandos tenham não significa ficar girando em torno deste saber. Partir significa pôr-se a caminho, ir-se, deslocar-se de um ponto a outro e não ficar, permanecer. Jamais disse como às vezes sugerem ou dizem que eu disse que deveríamos girar embevecidos, em torno do saber dos educandos, como mariposas em volta da luz. Partir do "saber de experiência feito" para superá-lo não é ficar nele.

A passagem da consciência real (efetiva) ${ }^{10}$ para a consciência máxima possível, a superação do "saber de experiência feito”, mediante um processo dialógico e problematizador, é buscada por meio da Investigação Temática. ${ }^{11}$ Nesta, identificado o Tema Gerador, parte-se para a Redução Temática, etapa em que é fundamental o questionamento: quais campos de conhecimentos são necessários para a compreensão e superação da situação significativa presente no tema? Num processo de planejamento coletivo e interdisciplinar, cabe aos especialistas selecionar quais conhecimentos/conteúdos de sua área serão necessários para a compreensão do tema.

Nas palavras de Freire (1987, p. 115):

[...] feita a delimitação temática, caberá a cada especialista, dentro de seu campo, apresentar à equipe interdisciplinar o projeto de "redução" do tema. No processo de "redução" deste, o especialista busca os seus núcleos fundamentais que, constituindo-se em unidades de aprendizagem e estabelecendo uma seqüência entre si, dão a visão geral do tema “reduzido".

\footnotetext{
${ }^{10}$ Freire (1987) discute as categorias “consciência real (efetiva)” e “consciência máxima possível” tendo como referência as idéias de Goldman, sendo que na primeira "os homens se encontram limitados na possibilidade de perceber mais além das "situações-limites” e a segunda identifica-se com as “soluções praticáveis despercebidas” (p.107). Essas categorias, respectivamente, são análogas às categorias consciência ingênua e consciência crítica, adotadas por Freire em momentos anteriores.

11 A Investigação Temática pode ser compreendida mediante o desenvolvimento de um processo sistematizado por Delizoicov (1991), em cinco etapas: Primeira: "levantamento preliminar", que consiste em reconhecer o ambiente em que vive o aluno, seu meio, seu contexto; Segunda: escolha de situações que sintetizam as contradições vividas, bem como a escolha de codificações; Terceira: realização de diálogos decodificadores, obtendo destes os temas geradores; Quarta: Redução Temática, a qual consiste em um trabalho de equipe interdisciplinar, com o objetivo de elaborar o programa e identificar quais conhecimentos são necessários para o entendimento dos temas, e Quinta: desenvolvimento do programa em sala de aula.
} 
Importante destacar que na Redução Temática - quarta etapa da Investigação Temática - os temas são configurados como conteúdos programáticos e que os conhecimentos cotidianos e científicos, problematizados/apropriados pelos sujeitos, na quinta etapa (desenvolvimento do programam em sala de aula) visam a superação da consciência ingênua. ${ }^{12}$

Ressaltamos que a busca de uma compreensão crítica da realidade não ocorre apenas na etapa da Redução Temática. Ela se inicia na identificação/problematização de elementos presentes no "mundo da vida", permeando todo o processo, incluindo a etapa posterior à Redução Temática: desenvolvimento do tema junto aos educandos.

No entender de Delizoicov (1991), os critérios aplicados durante a Redução Temática são epistemológicos. O autor afirma que os conhecimentos científicos são previamente selecionados e estruturados antes de serem desenvolvidos em sala de aula, “constituindo conteúdos programáticos escolares críticos e dinâmicos” (p.181). Esclarece, ainda, que a não-consideração do processo da Redução Temática tem como uma das conseqüências a suposição de não haver estruturação prévia de conhecimentos historicamente produzidos, aspecto que não condiz com a proposta de Freire.

Não raras vezes esta etapa tem sido ignorada. Alguns autores, ao abordarem configurações curriculares balizadas por Temas Geradores, propostos por Freire (1987), incorrem nesta omissão. Na interpretação de Delizoicov (1991), Libâneo, ao analisar o que denomina de tendência progressista libertadora, comete este aligeiramento. Este menciona os Temas Geradores como sendo "extraídos da problematização da prática de vida dos educandos”, porém não dá destaque ao papel dos conhecimentos historicamente produzidos. Segundo Delizoicov, Libâneo afirma que:

[...] os conteúdos tradicionais são recusados porque cada pessoa, cada grupo envolvido, na ação pedagógica dispõem em si próprios, ainda que de forma rudimentar, dos conteúdos necessários dos quais se parte. O importante não é a transmissão de conteúdos específicos, mas despertar uma nova forma da relação com a experiência vivida (Libâneo, 1987 apud Delizoicov, 1991, p. $151)$.

Delizoicov (1991) adverte que tal omissão tem gerado a acusação de que as ações pedagógicas, baseadas na concepção freireana, são “espontaneístas” e “reducionistas”. Entendemos que, possivelmente, em razão desse esquecimento,

\footnotetext{
${ }^{12}$ Ou seja, a passagem da consciência ingênua para a consciência crítica, que possibilita aos sujeitos compreenderem e transformarem o mundo em que vivem.
} 
muitas análises apresentam a compreensão de que, no encaminhamento freireano, fica-se "rodopiando", apenas, em torno do "saber da experiência” dos educandos.

Como síntese das idéias de Freire, ressaltamos a expressão de Gadotti (1997, p.5), segundo a qual "ensinar é inserir-se na história, não é só estar na sala de aula, mas num imaginário político mais amplo”. O autor revela que, para Freire, o conhecimento deve constituir-se numa ferramenta essencial para intervir no mundo, e que conhecemos para: a) entender o mundo (palavra e mundo); b) averiguar (certo ou errado, busca da verdade e não apenas trocar idéias); c) interpretar e transformar o mundo.

\section{Possíveis aproximações e distanciamentos}

Com a intenção de compreender as possíveis contribuições de Freire e Vigostki quanto ao processo de ensino/aprendizagem e seus desdobramentos, buscamos explicitar possíveis aproximações e distanciamentos entre ambos, de modo a fomentar as nossas produções curriculares para a educação básica e superior, processo permeado pelo adensamento na teorização sobre a aproximação entre estes dois referenciais. Entendemos que há aspectos complementares entre o pensamento de Freire e Vigotski que potencializam as ações tanto na formação docente quanto nas organizações curriculares.

Algumas aproximações entre as idéias de Freire e Vigotski são mencionadas por Gadotti (1996) ao destacar que o ponto de convergência entre as idéias destes autores é a importância dada à abordagem interacionista na alfabetização, bem como o interesse pela questão da linguagem e dos aspectos fundamentais relativos a mudanças sociais e educacionais. Segundo Moura (2001), ambos entendiam que a alfabetização não era um ato de memorização mecânica de aspectos desvinculados do universo existencial dos estudantes, mas uma atividade de criação e recriação e que existiam influências socioculturais sobre a capacidade cognitiva dos sujeitos. Neste contexto, a autora explicita pontos de convergência entre Freire e Vigotski, a exemplo da linguagem, papel do professor, vertente marxista, diálogo, concepção de sujeito e educação. De forma semelhante, Marques e Marques (2006) salientam que a interlocução entre os autores está vinculada a questões como: concepção de sujeito, de educação e de conhecimento, bem como a linguagem e consciência.

Neste trabalho procuramos enfocar outros aspectos que possam ser consideramos complementares entre as idéias de Freire e Vigotski e, possivelmente, 
não identificados nas obras citadas anteriormente. Assim, considerando possíveis distanciamentos, temos em Freire a problematização (presente no processo de Investigação/Redução Temática) e em Vigotski a intencionalidade da Significação Conceitual em contextos de interações sociais desde o início do processo pedagógico interativo. Em termos de aproximações, destacamos três dimensões as quais, tal qual os possíveis distanciamentos, constituem desafios para investigações futuras: a) a valorização e respeito do/ao conhecimento cotidiano; b) as semelhanças entre o papel dos especialistas em Freire (1987) e dos sujeitos mais capazes em Vigotski (2001), e c) a conscientização.

\section{A valorização e o respeito do/ao conhecimento cotidiano}

Quanto à valorização e ao respeito dos/aos conhecimentos dos alunos chamados de cotidianos ou saberes da experiência -, na concepção de Freire (1987) ela ocorre desde a problematização das situações vivenciais dos sujeitos e se mantém durante todo o processo da Investigação Temática, e não apenas em uma de suas etapas. Assim, podemos dizer que os saberes dos estudantes são importantes tanto na Redução Temática (FREIRE, 1987) quanto na significação do Sistema Conceitual (VIGOTSKI, 2001), permitindo um diálogo fecundo entre as pessoas quanto às suas vivências e às explicações dos saberes estruturados. Nesse viés, o conhecimento cotidiano não deve ser ignorado e nem substituído pelo científico.

Essa concepção é compartilhada por Freire (1993), quando este argumenta que não devemos descartar as compreensões dos estudantes sobre o mundo que os circunda, nem, tampouco, desconsiderá-las diante de um conhecimento mais elaborado, como o científico. Conforme discussão realizada no item 2.2, entretanto, Freire (1993) esclarece que não podemos ficar "rodopiando" em torno dos conhecimentos cotidianos, mas devemos buscar um novo conhecimento para além da valorização das concepções dos educandos. Por sua vez, Vigotski considera que a consciência dos conhecimentos do cotidiano só se torna possível com a significação de um conhecimento de maior generalidade.

\section{Semelhanças entre o papel dos especialistas e dos sujeitos mais capazes}

Para que esse processo seja possível, na Redução Temática, Freire (1987) recorre aos especialistas para colaborarem na definição dos conhecimentos científicos de cada área, indispensáveis para a compreensão do tema em questão. Nesse sentido, 
os temas norteiam a seleção dos conhecimentos a serem trabalhados. Os especialistas definem o conhecimento científico como um aporte, algo novo para o contexto dos temas. Sem a participação deles os conteúdos programáticos girariam apenas em torno dos conhecimentos dos educandos, aspecto fortemente criticado por Freire (1993).

Com base em Freire (1987), entendemos que especialistas são os integrantes da equipe interdisciplinar e que colaboram na estruturação do tema, de forma diferenciada, não ressaltando a expressão "mais capazes”. Para ele, todas as pessoas possuem conhecimentos, ainda que diferentes, mas importantes para a equipe no processo de compreensão e transformação do mundo. Em Vigotski, os sujeitos têm compreensões de níveis diferenciados e isso é importante no processo de significação, com produção diferenciada de sentidos e significados sobre o contexto em questão.

Nesse sentido, a Redução Temática parece apresentar semelhanças com o que Vigotski (2001) denomina de Zona de Desenvolvimento Proximal (ZDP). Esta entendida como o espaço no qual, graças à interação e à colaboração de outros mais capazes, uma determinada pessoa pode realizar uma tarefa de maneira e em nível que não seria capaz de alcançar individualmente. De acordo com Vigotski (2001), esse processo é de suma importância, uma vez que a aprendizagem se dá em interações ainda não amadurecidas, ou seja, “a aprendizagem só é boa quando está à frente do desenvolvimento” (p. 334).

Ainda quanto à ZDP, cabe destacar que alguns aspectos do ambiente familiar em que Vigotski viveu podem ter influenciado sua concepção dessa dinâmica. Nascido em uma família judia de classe média, que vivia praticamente isolada por causa da repressão sofrida na Rússia pré-revolucionária, teve a maior parte de sua educação formal realizada em casa, por meio de tutores particulares. Assim, passou a freqüentar a escola somente depois de seus 15 anos. No entender de Blanck (1996), a educação recebida de tutores talvez tenha sido uma das fontes da concepção de Vigotski sobre a ZDP.

Em vista do exposto, as idéias de Freire e Vigotski parecem convergir na função do especialista na etapa da Redução Temática (FREIRE, 1987) e dos sujeitos mais capazes na dinâmica da ZDP, durante a significação do Sistema Conceitual (VIGOTSKI, 2001). Ou seja, estariam os especialistas em Freire e os sujeitos mais capazes em Vigotski assumindo funções relativamente semelhantes?

\section{A conscientização}


Outro aspecto a destacar quanto a uma possível aproximação entre os autores diz respeito à constituição da consciência. De acordo com Marques e Marques (2006), em Vigotski a consciência é a capacidade do sujeito de refletir sobre a sua própria atividade e, com isso, tomar consciência dela. Em Freire a consciência parte das relações dialéticas consciência-mundo, em que os homens são consciência de si e do mundo.

De forma semelhante, entende-se que a consciência tanto em Freire quanto em Vigotski pode ser o ponto de chegada (Quadro 1), porém ambos possivelmente seguem caminhos diferenciados para chegar até ela. Em Freire (1987), conforme discussão anterior, a conscientização é vista como a superação da consciência real (efetiva) por meio do processo de Investigação/Redução Temática, constituído de cinco etapas. Freire via esta consciência crítica como necessária para compreender e transformar o mundo em que vivem os educandos.

Em Vigotski a formação da consciência se dá a partir da significação dos conceitos científicos, pois estes possibilitam à pessoa o entendimento das ações do cotidiano e saber que sabe. As novas interações produzidas na formação intencional e sistemática da consciência da realidade constituem psicologicamente o sujeito. Em outras palavras, o ponto de chegada é a consciência, isto é, saber que sabe, possibilitando ao sujeito uma compreensão do mundo em que vive, para, então transformá-lo na recriação cultural.

\section{Problematização e Significação Conceitual}

A partir dos Esquemas I e II apontamos, num primeiro momento, para o fato de que as idéias destes autores podem apresentar aspectos divergentes na gênese do conhecimento e no ponto de partida do processo de aprendizagem.

Vigotski buscou explicar como o conhecimento se processa na mente do sujeito, dando ênfase à psicogênese. Sua preocupação central girava em torno da constituição do sujeito e seu desenvolvimento pela aprendizagem e na evolução da relação pensamento e linguagem.

Freire não se preocupou explicitamente com o modo como se processa o conhecimento na mente dos sujeitos, mas, sim, em explicitar o que vem a favorecer a construção deste conhecimento, baseado, principalmente, na curiosidade epistemológica. Nesse sentido, talvez as duas teorias possam ser vistas como complementares. 
O ponto de partida no processo de aprendizagem, para Vigotski (2001), é a palavra, que desde o início é uma generalização ou um conceito. A palavra é tratada como signo e é central na abordagem vigotskiana. Assim, o seu interesse volta-se para os conceitos que permitem entender a vivência das pessoas e a gênese de novas funções mentais.

Em Freire (1987), por outro lado, o ponto de partida é caracterizado pela vivência dos sujeitos, as contradições existenciais, os problemas e não o conceito abstrato. Na concepção de Freire e Faundez (2002), o conceito necessita ser caracterizado como mediador para a compreensão da realidade, ao argumentarem que:

Não se deve partir do conceito para entender a realidade, mas sim partir da realidade para, através do conceito, compreender a realidade [...] o conceito deve ser considerado como mediação para compreender a realidade. Este conceito não pode ser considerado como absoluto não transformável (Freire; Faundez, 2002, p. 63).

Tal processo, no entender de Freire e Faundez (2002), significa "uma nova concepção da ciência” como mediadora para a compreensão e transformação da realidade. Estes aspectos têm implicações pedagógicas baseadas, sobretudo, no ato de conhecer: o querer conhecer, ou seja, a curiosidade epistemológica. Aspectos que, no entender de Freire (1996), são fundamentais no processo educacional. Parece-nos que Vigotski, no entanto, com base no materialismo dialético, também via a questão da palavra (em significação conceitual) como mediadora para compreender a vivência, porém entendemos que tal constatação precisa ser melhor analisada. Então, a palavra em Vigotski e a problematização em Freire podem ser consideradas como pontos de divergência, no processo educacional? Em outros termos: o ponto de partida, no processo educacional, segundo proposição destes dois autores, é distinto? Se, no entanto, considerarmos a problematização como parte de um processo que busca novos sentidos para as vivências, num processo dialógico, então temos, novamente, possíveis convergências entre os autores.

\section{Considerações Finais}

As discussões acerca das idéias de Freire e Vigotski, em síntese, compreendem: a) possíveis aproximações: função do especialista em Freire e do sujeito mais capaz em Vigotski; respeito/valorização do conhecimento cotidiano dos estudantes; a conscientização (com caminhos distintos); b) distanciamentos: na gênese do conhecimento (ponto de partida do processo educacional em Vigotski parece estar 
associado à significação conceitual e em Freire à problematização das situações existenciais).

Essas reflexões, todavia, são preliminares e interpretadas como um "estudo inicial” no campo teórico. As teorizações, empreendidas neste trabalho, instigam-nos a avançar, teórica e empiricamente, para possíveis aproximações entre as idéias de Freire e Vigotski. Nesse contexto, Gehlen, Auth e Auler (2008) exploraram aspectos que podem ser complementares entre os dois autores analisados no campo empírico, realizado no âmbito de propostas curriculares para a Educação em Ciências: Situação de Estudo (MALDANER, 2007) e Abordagem Temática (DELIZOICOV; ANGOTTI; PERNAMBUCO, 2002).

Por fim, ao constatar o quanto são raros os estudos e pesquisas que buscam uma aproximação entre as concepções de Freire e Vigotski, no contexto educacional, especificamente na Educação em Ciências, evidencia-se a necessidade de dar continuidade às investigações. Mesmo tendo em mente que Freire e Vigotski produziram suas obras em contextos, tempos e locais distintos, pretendemos avançar no campo teórico-prático, buscando novos referenciais que possivelmente possam enriquecer a elaboração e a compreensão dos significados produzidos em propostas curriculares para a Educação em Ciências, tais como a Situação de Estudo e a Abordagem Temática.

\section{Referências}

AGUIAR, O.A.; MORTIMER, F. Tomada de consciência de conflitos: análise da atividade discursiva em uma aula de Ciências. In: Investigações em Ensino de Ciências, vol. 10, n. 2, ago 2005 . Disponível em: http://www.if.ufrgs.br/public/ensino/revista.htm

ANGOTTI, J. A. Fragmentos e totalidade no conhecimento científico e no ensino de Ciências. São Paulo: FEUSP, 1991. (Tese).

AULER, D. Interações entre Ciência-Tecnologia-Sociedade no contexto da formação de professores de Ciência. Florianópolis: CED/UFSC, 2002. (Tese).

BLANCK, G. Vygotsky: o homem e sua causa. In: MOLL, C. Vygotsky e a Educação: implicações pedagógicas da psicologia sócio-histórica. Trad. Fani A. Tesseler. Porto Alegre: Artmed, 1996.

COELHO, J. C. A chuva ácida na perspectiva de Tema Social: um estudo com professores de Química em Criciúma (SC). Florianópolis: PPGECT/UFSC, 2005. (Dissertação).

COLE, M.; SCRIBNER, S. Introdução. In: Vigotski, L. S. A Formação Social da Mente. 6 ed. São Paulo: Martins Fontes, 1998. 
DANIELS, H. Vygotsky e a Pedagogia. Trad. Milton Camargo Mota. São Paulo: Loyola, 2003.

DELIZOICOV, D. N. Conhecimento, Tensões e Transições. São Paulo: FEUSP, 1991. (Tese).

DELIZOICOV, D.; ANGOTTI, J. A. Física. São Paulo: Cortez, 1991.

DELIZOICOV, D.; ANGOTTI, J. A. P; PERNAMBUCO, M. C. A. Ensino de Ciências: Fundamentos e Métodos. São Paulo: Cortez, 2002.

DUARTE, N. A anatomia do homem é a chave da anatomia do macaco: A dialética em Vigotski e em Marx e a questão do saber objetivo na educação escolar. Educação \& Sociedade, ano XXI, n.71, julho de 2000, p.79-115.

FERREIRA, R. S.; JÚNIOR, A. L. A construção do conhecimento biológico nas séries iniciais: o papel das interações discursivas em sala de aula. In: V Encontro Nacional de Pesquisa em Educação em Ciências (ENPEC), Bauru/SP, 2005.

FREIRE, A. M. A. A voz da esposa: a trajetória de Paulo Freire. In: GADOTTI, M. (org.). Paulo Freire: uma bibliografia. São Paulo: Cortez, 2001.

Pedagogia da Autonomia: saberes necessários à prática educativa. Rio de Janeiro: Paz e Terra, 1996.

Pedagogia do Oprimido. 17 ed. Rio de Janeiro: Paz e Terra, 1987.

Pedagogia da esperança: um reencontro com a pedagogia do oprimido. 2 ed. Rio de Janeiro, Paz e Terra, 1993.

FREIRE, P.; FAUNDEZ, A. Por uma pedagogia da pergunta. Rio de Janeiro: Paz e Terra, 2002.

FREIRE, P.; GUIMARÃES, S. A África ensinando a gente: Angola, Guiné-Bissau, São Tomé e Príncipe. São Paulo: Paz e Terra, 2003.

FREIRE, P.; MACEDO D. Alfabetização: Leitura do mundo leitura da palavra. Rio de Janeiro: Paz e Terra, 1990.

GADOTTI, M. (org.) Paulo Freire: uma bibliografia. São Paulo: Cortez, 1996.

GADOTTI, M. Lições de Freire. Rev. Fac. Educ. vol. 23 n. 1-2 São Paulo Jan./Dec. 1997. Disponível em http://www.scielo.br/scielo.php?pid=S010225551997000100002\&script=sci_arttext. Acesso em maio de 2005.

GASPAR, A.; MONTEIRO, I. C. C.; Atividades experimentais de demonstrações em sala de aula: uma análise segundo o referencial da teoria de Vigotski. In: Investigações em Ensino de Ciências, vol. 10, n. 2, agosto de 2005. Disponível em: http://www.if.ufrgs.br/public/ensino/revista.htm.

GEHLEN, S.T. Temas e Situações Significativas no Ensino de Ciências: Contribuições de Freire e Vigotski. Ijuí: Ed. Unijuí, 2006. (Dissertação).

GEHLEN, S. T.; AUTH, M. A.; AULER, D. Contribuições de Freire e Vygotsky no contexto de propostas curriculares para a Educação em Ciências. In: REEC - Revista Electrónica de Enseñanza de las Ciencias. Vol. 7, No 1, 65-83, 2008. Disponível em: http://saum.uvigo.es/reec/ 
MALDANER, O. A. Situações de Estudo no Ensino Médio: nova compreensão de educação básica. In: Nardi, R. (Org.). Pesquisa em Ensino de Ciências no Brasil: alguns recortes. São Paulo: Escrituras. p. 237-253, 2007.

MALDANER, O. A. e ZANON, L. B. Situação de Estudo: uma Organização do Ensino que Extrapola a Formação Disciplinar em Ciências. Espaços da Escola. Ijuí: ano 11, n. 41, p. 45-60, 2001.

MARQUES, L. P.; MARQUES, C. A. Dialogando com Paulo Freire e Vygotsky sobre Educação. In: $\mathbf{2 9}^{\circ}$ Reunião Anual da Anped (Associação Nacional de Pós-Graduação e Pesquisa em Educação). Caxambu/MG, 2006.

MORTIMER, E. F. Linguagem e formação de conceitos no ensino de Ciências. Belo Horizonte: Editora UFMG, 2000.

MORTIMER, E. F; SCOTT, P. Atividade discursiva nas salas de aula de ciências: uma ferramenta sociocultural para analisar e planejar o ensino. In: Investigações em Ensino de Ciências, Vol. 7, N. 3, dezembro de 2002. Disponível em: http://www.if.ufrgs.br/public/ensino/revista.htm.

MOURA, T. M. M. Aproximações entre as idéias de Freire e Vygotsky: importância para a prática pedagógica com jovens e adultos. In: Colóquio Internacional Paulo Freire. Recife/PE, 2001.

PANSERA-DE-ARAÚJO, M. C.; AUTH, M. A.; MALDANER, O. A. Identificação de características de inovação curricular em Ciências Naturais e suas tecnologias através de Situações de Estudo. In: V Encontro Nacional de Pesquisa em Educação em Ciências (ENPEC). Bauru/SP, 2005.

PERNAMBUCO, M. C. A; et al. Projeto "ensino de ciências a partir de problemas da comunidade". In: Ciência integrada e/ou integração entre as Ciências teoria e prática. Rio de Janeiro: UFRJ, 1988.

POZO, J.A.; SANZ, A.; GÓMEZ CRESPO, M.A.; LIMÓN, M. Las ideas de los alumnos sobre la Ciencia: una interpretación desde la Psicología cognitiva. Enseñanza de las Ciencias, v.9, n.1, p. 83-94, 1991.

ROSA, A.; MONTERO, I. O contexto histórico do trabalho de Vygotsky: uma abordagem sócio-histórica. In. MOLL, L. C. Vygotsky e a Educação: implicações pedagógicas da psicologia sócio-histórica. 2 ed. Trad. Fani A. Tesseler. Porto Alegre: Atmed. 2002.

REGO, T. C. Vygotsky: uma perspectiva histórico-cultural da educação. Petrópolis: Vozes, 1995.

A origem da singularidade humana na visão dos estudantes. In: Implicações Pedagógicas do Modelo Histórico-Cultural. Cadernos Cedes, ano xx, n.35, julho de 2000, p. 96-113.

RODRÍGUEZ AROCHO, W. El tema de la conciencia en la psicología de Vygotski y en la pedagogía de Freire: implicaciones para la educación. X Encuentro Nacional de Educación y Pensamiento: Globalización, Pensamiento Crítico e Pedagogía de la Liberación. Homenaje Póstumo a Paulo Freire. San Juan/Puerto Rico, 2000. Disponível em: www.pddpupr.org/publicaciones_actas.htm

SANTOS, W. L. P. Aspectos Sociocientíficos em aulas de Química. Tese: FaE/UFMG, Belo Horizonte, 2002. 
SILVA, A.F. G. A construção do currículo na perspectiva popular e crítica das falas significativas às práticas contextualizadas. São Paulo: PUCSP, 2004.(Tese).

VIGOTSKI, L.S. A Construção do Pensamento e da Linguagem. 1 ed. Trad. Paulo Bezerra. São Paulo: Martins Fontes, 2001.

VIGOTSKI, L.S. A Formação Social da Mente: o desenvolvimento dos processos psicológicos superiores. 6 ed. Trad. José C. Neto, Luís S.M. Barreto e Solange C. Afeche. São Paulo: Martins Fontes, 1998. 